\title{
CICLO DE VIDA DE Corynelia tropica, PATÓGENO FOLIAR EN Podocarpus saligna
}

\author{
(Life cycle of Corynelia tropica, leaf pathogen on Podocarpus saligna)
}

Moisés Osorio Oliva .

Ex-Académico. Universidad Austral de Chile, Facultad de Ciencias Forestales, Valdivia, Chile. moisesyoguiloa@gmail.com

RECIBIDO: 29 de Septiembre de 2015

APROBADO:15 de Octubre de 2015

\section{EL AUTOR DECLARA NO TENER CONFLICTO DE INTERESES}

Palabras claves: Corynelia tropica en Podocarpus saligna, ciclo de vida.

Key words: Corynelia tropica on Podocarpus saligna, life cycle.

\section{RESUMEN}

El presente estudio tuvo como objetivo determinar el ciclo de vida de Corynelia tropica, patógeno de hojas y ramillas en mañío de hoja larga (Podocarpus saligna). Mensualmente se recolectaron ramillas de $P$. saligna. En la medida que se fueron detectando estadíos interesantes dentro del ciclo de vida de este patógeno, la frecuencia de las colectas se intensificó en forma quincenal, e incluso semanal. Se pudo constatar que $C$. tropica presentó un ciclo de vida anual muy definido, con gran regularidad en la aparición y desarrollo de sus estructuras fructíferas. Invariablemente el ciclo de vida se inició en la primera quincena de noviembre con la inoculación de los nuevos brotes de $P$. saligna. A inicios de enero se manifestaron los primeros síntomas de la infección y a comienzos de marzo ya eran notorias las estructuras del anamorfo. A fines de mayo las estructuras del teleomorfo se hacían protuberantes y se iniciaba la formación de los ascos. A fines de julio los ascocarpos presentaban forma y tamaño ya adulto, y las ascosporas al interior de los ascos se encontraban en proceso de maduración. A fines de octubre las ascosporas ya estaban maduras y su liberación a comienzos de noviembre, sincronizaba con la emergencia de los brotes de $P$. saligna, con lo que se daba inicio una vez más a un nuevo ciclo de vida de $C$. tropica. Se pudo constatar que además del follaje y ramas, este patógeno también atacaba a los frutos de P.saligna.

\section{ABSTRACT}

This study aimed to determine the life cycle of Corynelia tropica, pathogen leaves and twins in longleaf mañío (Podocarpus saligna). Monthly $P$. saligna twigs were collected. As they were detecting interesting stages in the life cycle of this pathogen, the frequency of collections were intensified fortnightly or even weekly. It was found that C. tropica presented a very defined, with great regularity in the occurrence and development of their fruiting structures annual life cycle. Invariably the life cycle began in the first half of November with the inoculation of new outbreaks of $P$. saligna. In early January the first symptoms of infections manifested and early March were already notorious the anamorph structure. In late May teleomorph structures became prominent and the formation of 
the asci began. In late July the ascocarps presented adult size and shape, and the ascospores within the asci were maturing. In late October ascospores were ripe and in early November, release synchronized with outbreaks of $P$. saligna, which was given start again a new life cycle of $C$. tropica. It was found that besides the foliage and branches, this pathogen also attacked the fruits of $P$. saligna.

\section{INTRODUCCIÓN}

El mañío de hoja larga (Podocarpus saligna $\mathrm{D}$. Don) es una especie endémica de los bosques del centro-sur de Chile y de los territorios adyacentes del suroeste de Argentina. Son árboles dioicos, de hasta $20 \mathrm{~m}$ de altura, con copa muy ramosa y de hábito piramidal más o menos redondeado. Su tronco es recto y cilíndrico, y puede alcanzar hasta $1 \mathrm{~m}$ de diámetro. Posee ramas abundantes, flexuosas y largas. Todas estas características le confieren a estos árboles un especial atractivo desde el punto de vista ornamental. Por sus hojas verdes, perennes, compuestas, largas y puntudas, las ramas se utilizan para arreglos florales, y se comercializan tanto en el mercado local chileno, como en el mercado internacional (Morales 2013). Su madera de color amarillo claro, de textura fina y homogénea, y de veteado suave, se emplea en la fabricación de muebles, cajonería, embalajes, tornería, y contrachapados para diversos usos (Diaz-vaz 1987). Según Donoso (1978), probablemente el mejor uso que se le puede dar a esta especie es como planta ornamental y de sombra.

Con relación a las patologías del P. saligna, es poco lo que registra la literatura especializada. Una de las patologías más destacadas es la que dice relación con el hongo Corynelia tropica (Auersw. y Rabenh.) Starbäck. Según Butin y Peredo (1986), este agente corresponde a un parásito primario que se presenta inicialmente en hojas vivas y ocasionalmente sobre la corteza de ramas jóvenes.

En Patología Forestal, en general existe bastante información relacionada con aspectos morfológicos y taxonómicos de los agentes cau- santes de enfermedades. No obstante, hay falencia respecto de estudios relacionados con los ciclos de vida de los patógenos, lo cual no permite incursionar adecuadamente en el control de las mismas. En Chile, esto se hace aún más crítico respecto de patógenos que afectan a especies forestales autóctonas, como es el caso de $P$. saligna.

En los diagnósticos sanitarios relacionados con P. saligna, atendidos en el Laboratorio de Patología Forestal de la Universidad Austral de Chile, se fue haciendo cada vez más frecuente la participación de C. tropica asociado a defoliaciones de mayor o menor intensidad y frente a las cuales, en general, los consultantes demandan por una acción terapéutica. Producto de ello, se planificó y dio inicio al presente estudio, el cual tuvo como objetivo, determinar el ciclo de vida de C. tropica en $P$. saligna. Esto, con el fin de aportar información que pudiese ser de utilidad tanto para control de este agente patógeno, como para estudios de carácter morfológico, taxonómico, y fisiológico, que a futuro se deseen abordar con más profundidad. De momento, los únicos antecedentes existentes sobre este tema, son los generados al inicio de este mismo estudio (Osorio 1996).

\section{MATERIALES Y MÉTODOS}

En su aspecto formal, el presente estudio tuvo una duración de dos años. Durante el primer año, mensualmente se colectaron ramillas árboles de $P$. saligna afectados por $C$. tropica, tanto en el Jardín Botánico (39 48' 16.2” S, 73 15'0.72” W) como en el Arboretum de la Universidad Austral de Chile (39 47' 59' S, 73 15' 42.9' W). Las muestras fueron obtenidas desde la parte baja de la copa de los árboles, a una altura de aproximadamente 1 a 1,5 m. Con el fin de enfatizar respecto de algunas etapas transicionales del ciclo de vida de este patógeno detectadas durante el primer año de estudio, las colectas periódicas de material se intensificaron en forma quincenal, e incluso semanal, durante el segundo año de esta investigación. El muestreo incluyó mayoritariamente a árboles juveniles de 
CICLO DE VIDA DE Corynelia tropica, PATÓGENO FOLIAR EN Podocarpus saligna - M. Osorio.

aproximadamente 10 a 20 años de edad, plantados artificialmente. Ocasionalmente, también se colectó material desde árboles adultos mayores de 20 años que se encontraban regenerando en forma natural. Adicionalmente, durante el segundo año se amplió el ámbito geográfico de las colectas de material, en forma azarosa, desde lugares adyacentes a la ciudad de Valdivia ( $39^{\circ} 48^{\prime} 30^{\prime \prime} \mathrm{S}, 73^{\circ} 14^{\prime} 30^{\prime \prime}$ $\mathrm{W})$, en un radio aproximado de hasta $50 \mathrm{~km}$. Éstas últimas muestras, eran colectadas generalmente desde árboles aislados, que se encontraban creciendo en los bordes de caminos rurales, o al interior de predios agrícolas y/o forestales. Luego de cada colecta, y lo más inmediatamente posible, el material fue analizado macroscópica y microscópicamente. Para determinar el estado de desarrollo de las estructuras internas contenidas en las fructificaciones asexuales y sexuales de $C$. tropica, se realizaron cortes micrométricos en fresco, sin uso de tinción. Una vez documentadas estas estructuras mediante fotografías, dibujos y mediciones, el material vegetal remanente, fue herborizado y rotulado para su eventual uso posterior. Con posterioridad a los dos años contemplados formalmente para la realización de este estudio, en forma esporádica y azarosa, se colectaron y analizaron muestras complementarias, con el fin de constatar si existía o no regularidad en la aparición y desarrollo de algunos de los estadíos más característicos del ciclo de vida de este patógeno, originalmente detectados.

\section{RESULTADOS}

Durante los dos primeros años programados para este estudio, y también en los muestreos azarosos complementarios realizados en años posteriores, se pudo constatar que el inicio del periodo vegetativo de $P$. saligna, caracterizado por la emergencia de nuevas ramas y follaje, se produjo invariablemente durante la primera quincena de noviembre (figuras 1A y 2A). Luego de ello, y transcurrido aproximadamente dos meses, a inicios de enero del siguiente año ya era posible visualizar los primeros síntomas del ataque de este C. tropi- $c a$, caracterizados por pequeñas manchas cloróticas, visibles tanto en el haz como en el envés de las hojas nuevas, las que se acentuaban en la segunda quincena del mes de enero. Casi simultáneamente, y principalmente en el envés de estas hojas, en cada una de las manchas cloróticas se comenzaba a hacer visible un tejido estromático emergente, en forma de una finísima línea negra de aproximadamente 3 a $7 \mathrm{~mm}$ de largo (figuras 1BC y 2B). En los casos más prematuros, durante este mismo período se pudo observar que el crecimiento de este tejido estromático desgarra la epidermis e inmersos en él y en forma agrupada, se iniciaba la formación de los picnidios que representan el estado anamorfo de C.tropica (figuras 1DE). A mediados de febrero ya era posible observar al microscopio, el inicio de la formación de células conidiógenas y de conidios al interior de estos picnidios (figuras 1GHI y 2C).

A comienzos de marzo, los picnidios se hacían cada vez más notorios y el tamaño individual de cada uno de ellos alcanzaba aproximadamente $0,5 \mathrm{~mm}$ de diámetro. El análisis microscópico de estas fructificaciones permitía visualizar en su interior la presencia de numerosas células conidiógenas bien desarrolladas y abundante producción de conidios (figuras 1GHI). Hacia fines de marzo, y durante todo abril, luego de eventos de lluvia prolongados y de alta humedad ambiental propios de esta zona de estudio, desde la parte superior de los picnidios se producía la exudación de conidios en forma de masa mucilaginosa de color hialino a blanquecino (figura 1F). Al contacto directo con el agua en estado líquido, estas masas de conidios se disgregaban fácilmente. Con la exudación de los conidios, comenzaba a culminar lentamente la fase asexual, la cual, en rigor, se había iniciado con la inoculación de los tejidos producidos en el período vegetativo en curso (figura 2C).

Desde comienzos de mayo ya era posible detectar el inicio de la fase sexual del ciclo de vida de $C$. tropica, el que se evidenciaba por la formación de ascocarpos agrupados que comenzaban a desarrollarse sobre el mismo estrato de tejido estromático en el que anteriormente se habían for- 


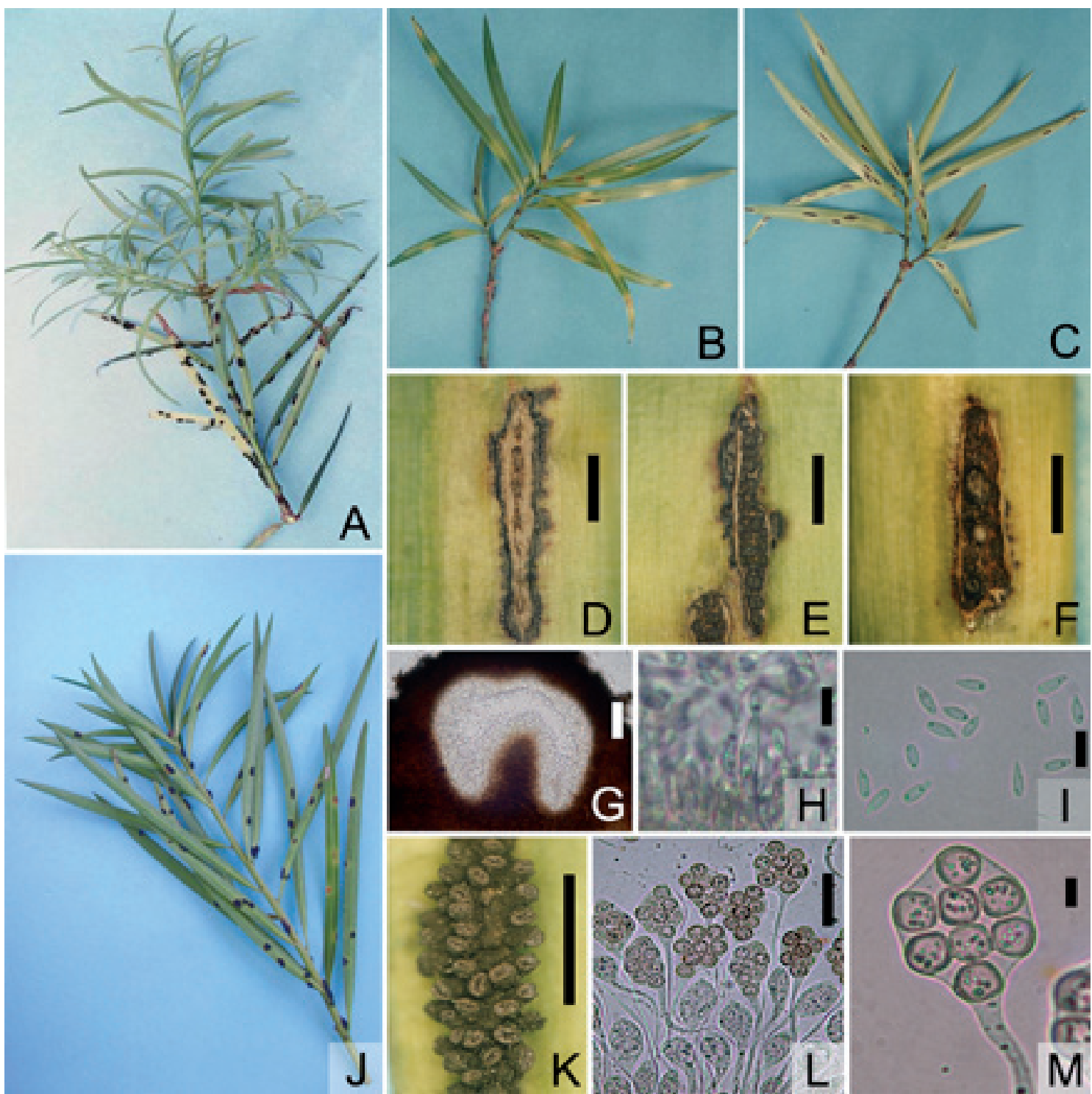

Figura 1. Manifestación de C. tropica en P. saligna. A) Se inicia el desarrollo de ramas y follaje del nuevo período vegetativo. Bajo éste, la rama y follaje del período vegetativo anterior se muestran fuertemente atacados por $C$. tropica. B) Comienza a manifestarse un nuevo ciclo de vida de C. tropica en P. salina. En el haz de las hojas recién desarrolladas se observan mayoritariamente los primeros síntomas de la presencia de C. tropica caracterizados por manchas cloróticas. C) En la misma muestra anterior, vista desde el envés, se observan mayoritariamente los primeros signos de la presencia de C. tropica caracterizados por estromas alargados de color negro. D) El desarrollo de los picnidios agrupados en el estroma comienza a rasgar la epidermis de la hoja. E) La epidermis ya rasgada deja expuestos a los picnidios. F) Conjunto de conidios a modo de gota mucilaginosa, exudados desde los picnidios luego de un período de lluvia. G) Corte transversal-vertical de un picnidio. Todo el contorno hialino de su interior se encuentra conformado por células conidiógenas. H) Células conidiógenas dando origen a conidios. I) Conidios. J) Próximo al término del período vegetativo en curso, en las ramas y follaje se observan ascocarpos bien desarrollados. K) Ascocarpos agrupados sobre un estroma. L) Himenio de un ascocarpo en el que se observan ascos en distintos grados de madurez. M) Asco con ascosporas ya maduras. Escalas de referencia: en $\mathrm{DEFK}=2 \mathrm{~mm}$; en $\mathrm{G}=100 \mu \mathrm{m}$, en $\mathrm{L}=50 \mu \mathrm{m}$, y en $\mathrm{HIM}=10 \mu \mathrm{m}$. 


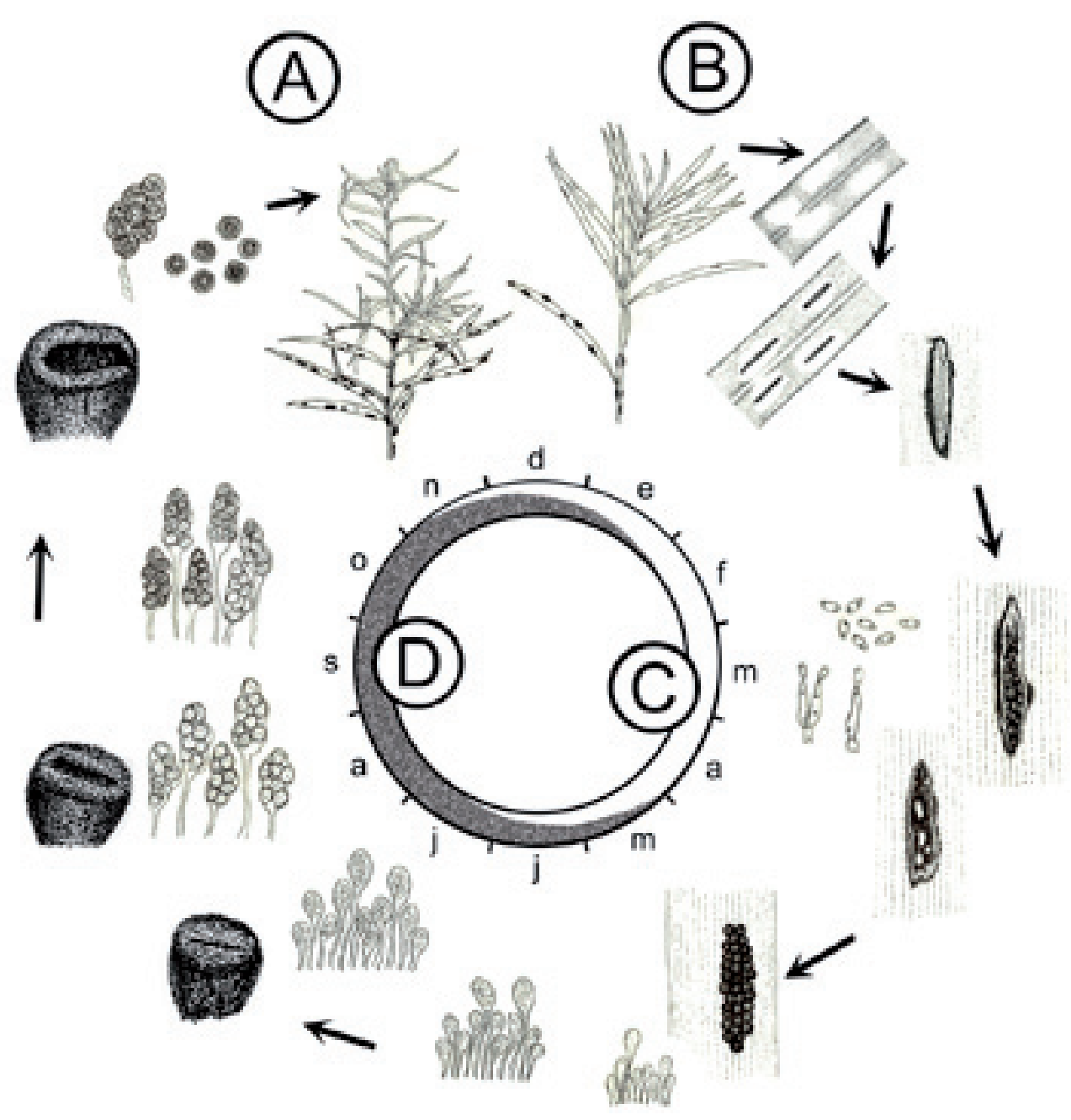

Figura 2. Ciclo de vida de C. tropica en P. saligna. A) Simultáneamente con el desarrollo del follaje y ramas del nuevo período vegetativo, se inicia el proceso de inoculación por parte de C. tropica. B) Comienza a hacerse evidente la presencia de $C$. tropica mediante la aparición de síntomas (manchas cloróticas) preferentemente en el haz de las hojas, y de signos (estromas alargados de color negro) mayoritariamente en el envés de las mismas. C) Fase asexual (sector en blanco). Formación, desarrollo y maduración de los picnidios. D) Fase sexual (sector en achurado). Formación, desarrollo y maduración de los ascocarpos.

mado los picnidios. De esta forma, en esta etapa del ciclo de vida de este patógeno, sobre un mismo estroma era posible observar picnidios ya sobremaduros, entremezclados con ascocarpos en desarrollo. Hacia fines de mayo los ascocarpos se hacían notoriamente protuberantes y en su interior ya era posible visualizar el inicio de la formación de los ascos. En general, en este período los ascos se observaban con un contenido protoplasmático in- diferenciado y todo el conjunto de tejido himenial era hialino (figura 2D). Excepcionalmente, era posible observar en esta fecha ascos con ascosporas en proceso de formación.

Durante el mes de junio y hasta mediados de julio, continuaba el desarrollo de los ascocarpos y simultáneamente iba quedando oculta la presencia de los picnidios en los estromas. A partir de esta fecha, tanto en el follaje como en las ramas 
desarrolladas en el periodo vegetativo en curso, los únicos signos visibles de la presencia de C. tropi$c a$ en $P$. saligna, eran los ascocarpos estromáticos. Hacia fines de julio los ascocarpos se presentaban de forma y de tamaño adulto. Al centro de la parte superior externa de ellos, ya se podía visualizar la zona de dehiscencia, a modo de una línea algo hundida, a través de la cual en un estado más avanzado sería liberado el inóculo (figura 2D). Al interior de los ascocarpos, la maduración de los ascos se presentaba como un proceso secuencial y ya en esa fecha era posible observar ascos con ascosporas hialinas en formación. En situaciones más avanzadas de desarrollo, también era posible observar algunos ascos con ascosporas de color pardo-claro, las cuales evidenciaban un cierto grado de maduración.

A medida que avanzaba el mes de agosto, externamente la zona de dehiscencia de los ascocarpos se hacía cada vez más notoria y en preparaciones microscópicas era posible observar en el interior de estos, una mayor cantidad de ascos bien formados, con abundante presencia de esporas pardo-claro, lo que evidenciaba un estado de maduración algo más avanzado de todas estas estructuras (figura 2D).

Durante septiembre e inicios de octubre, continuaba la maduración de los ascocarpos y de sus estructuras fértiles. Microscópicamente, se podía observar que en el interior de los ascocarpos se hacía cada vez más notoria la presencia de ascos con ascosporas prácticamente ya maduras, aún cuando todavía era posible observar también ascos con ascosporas en diferentes estados de madurez. Hacia fines de octubre los ascocarpos habían alcanzado su máximo desarrollo (figuras $1 \mathrm{JK}$ ) y en su interior era muy abundante la presencia de ascos con ascosporas ya maduras, las que se caracterizan por su color pardo oscuro (figuras 1LM). Por esa fecha, se visualizaban numerosos ascocarpos que presentaban en su parte superior externa la zona de dehiscencia ya desgarrada y todo el inóculo generado al interior de ellos, permanecía a la espera de sincronizar con la emergencia y desarrollo del nuevo follaje. En árboles de $P$. saligna fuertemente atacados por $C$. tropica, el follaje del último periodo vegetativo, en el cual se habían desarrollado estas fructificaciones, comenzaba a caer prematuramente, produciendo en los casos más extremos su pérdida total (figuras 1BC y 4B).

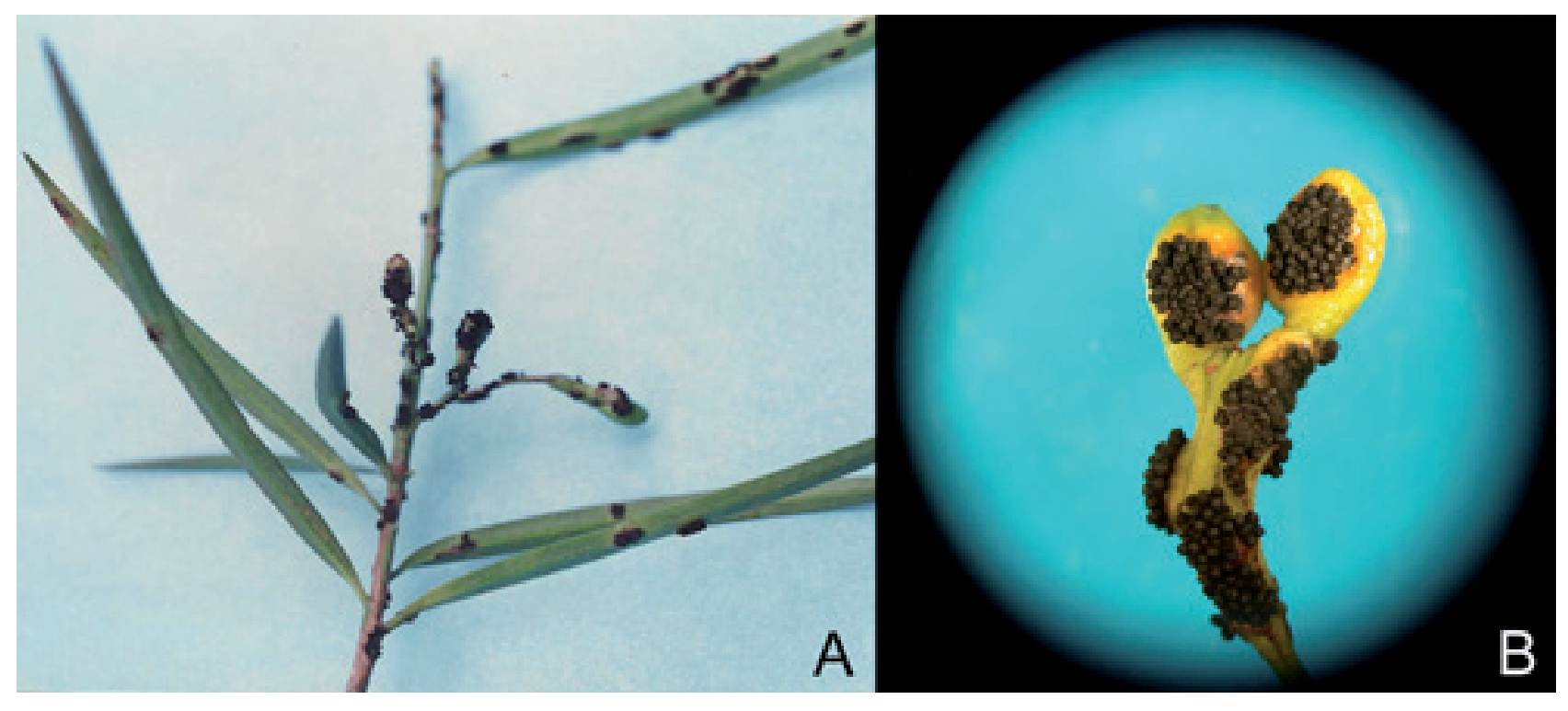

Figura 3. Corynelia tropica en tejidos de P. saligna. A) Fructificaciones estromáticas desarrollando en rama, follaje, y frutos. B) Vista microscópica de cuerpos fructíferos desarrollando sobre frutos. 


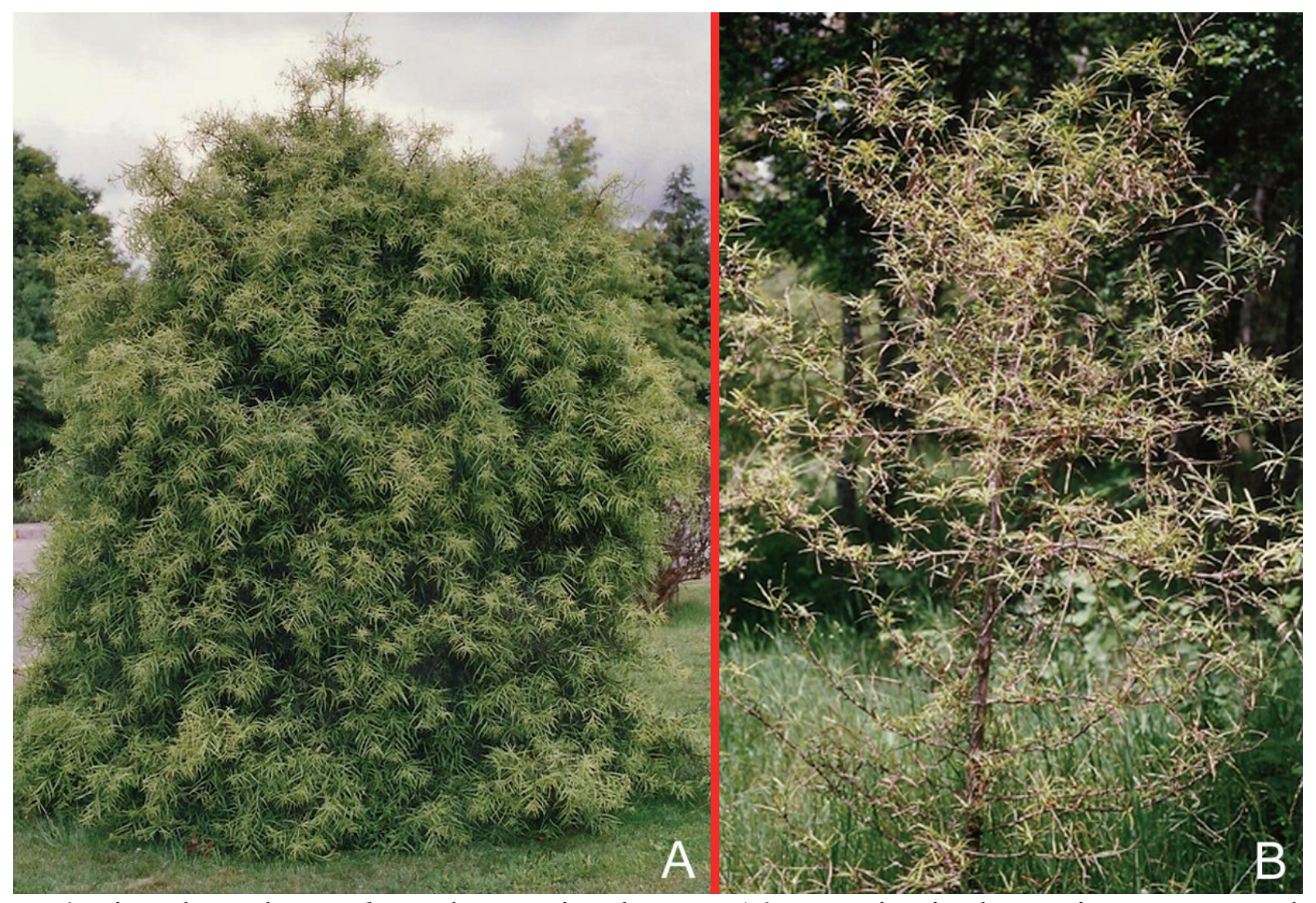

Figura 4. Ejemplares de P. saligna de aproximadamente 16 años, viverizados conjuntamente, y plantados en distintos sitios. A) Árbol aparentemente sano. B) Árbol fuertemente defoliado por el ataque de $C$. tropica.

Iniciado entonces un nuevo periodo vegetativo de $P$. saligna, una vez más se volvía a producir por parte de C. tropica la inoculación del follaje y ramas recién emergidas, y muy seguidamente aparecía la manifestación de los primeros síntomas de ataque hacia el mes de enero, dando origen así, a un nuevo ciclo de vida de este patógeno. De esta forma, el desarrollo de todos los síntomas y signos anteriormente descritos, se volvían a repetir en cada nuevo ciclo de vida de $C$. tropica en $P$. salig$n a$.

En el presente estudio, se pudo observar que este cuadro infeccioso provocado por C. tropica, también afectaba a los frutos de $P$. saligna (figuras $3 \mathrm{AB}$ ).

Todos los síntomas y signos aquí señalados se pudieron detectar tanto en árboles de regeneración natural, como en árboles plantados artificial- mente, principalmente en ejemplares localizados en sitios poco ventilados y/o carentes de suficiente luminosidad.

\section{DISCUSIÓN}

Respecto de la presencia de C. tropica en especies nativas chilenas, la mayoría de los trabajos desarrollados hasta ahora, han estado orientados principalmente a abordar aspectos descriptivos y taxonómicos. En algunos de los trabajos más pioneros, tanto la correcta identificación de este agente, como también su vinculación con los hospedantes involucrados, ha sido un tanto confusa confusa (Fitzpatrick 1920ab, 1942, Spegazzini 1923). Con posterioridad, Benny et al. (1985) y Minter 2006a, han contribuido a poner más claridad en este tema, sobre todo en lo que respecta a la relación de $C$. 
tropica con P. saligna.

De las siete especies de Corynelia descritas en la literatura específica (Minter 2006 abcdefg) sólo para $C$. tropica y para $C$. brasiliensis se entrega algún tipo de información relacionada con su ciclo de vida. En el caso específico C. tropica, que ha sido reportada en 14 hospederos distribuidos en ambos hemisferios (Minter 2006f) hasta ahora los únicos antecedentes existentes respecto de este tema, corresponden a un extracto compendiado de los resultados preliminares generados al inicio del presente estudio (Osorio 1996).

Ya con la información obtenida durante el primer año de ejecución de este trabajo, la que fue corroborada más en detalle durante el segundo año del mismo, y en muestreos azarosos realizados en años posteriores, se pudo constatar que el ciclo de vida de $C$. tropica en $P$. saligna es anual y muy bien definido. Corynelia tropica presenta una gran regularidad cronológica en el inicio de la formación y del desarrollo de estructuras fructíferas que caracterizan a este patógeno foliar, las que a su vez están en estrecha relación con la fenología de $P$. saligna, en lo que a la emisión de ramas, de follaje, $\mathrm{y}$ de frutos se refiere.

Butin y Peredo (1986), al hacer referencia a la patogenicidad y sintomatología de $C$. tropica tanto en Podocarpus andina como en P. saligna, sugieren que el ciclo de vida de este patógeno es de más de un año al señalar que no se constata, al menos durante el primer año de desarrollo del hongo, una alteración en los tejidos del hospedante, ya que las partes atacadas permanecen largo tiempo verdes y sin alterarse, y que solamente al final del desarrollo del hongo se presentan las primeras necrosis, las que llevan a una mayor o menor coloración café de las hojas y ramas atacadas. Sin embargo, en el presente estudio se pudo constatar que los primeros síntomas de la presencia de $C$. tropica en $P$. saligna, caracterizados por la formación de manchas cloróticas tanto en el haz como en el envés de las hojas nuevas, son posible visualizarlos ya al segundo mes, luego de la brotación de ésta.
Además, casi simultáneamente, y principalmente en el envés de las hojas, en cada una de las manchas cloróticas se comienzan a manifestar los primeros signos de la presencia de este patógeno, caracterizados por un tejido estromático emergente, en forma de una finísima línea negra (figuras 1BC y 2B), sobre el cual posteriormente se desarrollan los picnidios, que representan el estado anamorfo de $C$. tropica (figuras 1DEFGHI y 2C). Los resultados del presente estudio, son concordante con los obtenidos por Speer (1981), quien al analizar los estadíos de la patogénesis de Corynelia brasiliensis en Podocarpus lambertii, concluye que el ciclo de vida de ese patógeno, en ese hospedante, también es anual.

Durante la fase asexual del ciclo de vida de C. tropica, probablemente el agua de lluvia permite el escurrimiento de los conidios a través del follaje y ramillas del hospedante, facilitando el encuentro de propágulos de distinto sexo y que de esta forma se activen los mecanismos que dan inicio a la reproducción sexual. Esto está en concordancia con lo que señalan Butin y Peredo (1986) al sugerir que los conidios sirven probablemente para la fertilización del ascogonio o para la dicariotización del micelio haploide. En el caso de $C$. brasiliensis en $P$. lambertii, Speer (1981) señala que las observaciones disponibles son insuficientes para permitir precisar si los conidios son realmente órganos de dispersión o si ellos intervienen en fenómenos sexuales a modo de espermacios. A la luz de los antecedentes aportados respecto del período de formación y maduración de los picnidios, señalados en el ciclo de vida de $C$. tropica que aquí se entregan, en futuros estudios se podría abordar más en detalle este tema.

Respecto de C. tropica, Fitzpatrick (1942) señala que los espermogonios (término usado en la literatura para referirse también a los picnidios) y los ascocarpos, nacen usualmente en diferentes estromas, lo que no es concordante con lo observado en el presente estudio, en el que se pudo constatar que los ascocarpos se forman en los mismos es- 
tromas en los que antes estuvieron los picnidios. Probablemente lo señalado por este autor se daba a que, el material que utilizó para el diagnóstico de C. tropica, fue menos adecuado que el que tuvo para otras especies de Corynelia. Según lo señalado por este mismo autor, la mayor parte de los especímenes de C. tropica que examinó, fueron fragmentarios y contenían pocos ascocarpos. Algo parecido ocurre con lo expresado por Minter (2006f) al señalar entre otros aspectos que los conidiomatas (picnidios en el presente estudio) no se observan siempre, son poco visibles, a veces presentes sin ascomatas (ascocarpos en el presente estudio) a veces preceden y acompañan a los ascocarpos. A la luz de los resultados del presente estudio, el que algunos autores hayan detectado en ramas y follaje sólo picnidios estromáticos, y en otros casos sólo ascocarpos estromáticos, obedecería únicamente a la fecha de colecta y tipo de material utilizado en sus análisis y descripciones. De acuerdo al ciclo de vida aquí descrito (figura 2), se puede inferir que, desde enero y hasta aproximadamente fines de abril, las muestras de $P$. saligna atacados por $C$. tropica que contiene ramas y follaje exclusivamente del periodo vegetativo en curso, sólo deben presentar picnidios estromáticos en distintos grados de desarrollo. Del mismo modo, desde aproximadamente inicios de mayo y hasta mediados de julio, en las muestras colectadas que también contienen solamente tejidos vegetales del periodo vegetativo en curso, se deben encontrar conjuntamente tanto picnidios maduros a sobremaduros, como ascocarpos en desarrollo, compartiendo un mismo tejidos estromático. A partir de aproximadamente mediados de julio y hasta los primeros meses del año siguiente, las muestras de tejidos del último periodo vegetativo deben contener solamente ascocarpos en distintos grados de desarro1lo. De allí en adelante, las ramas y follaje atacado que permanezcan por más de un año adheridos al hospedante, sólo deben presentar ascocarpos estromáticos sobremaduros. En consecuencia, si desde enero y hasta fines de abril se colectan muestras no selectivas, que contengan tejidos vegetales de más de un periodo vegetativo, en la porción de las ramas y follaje del periodo vegetativo en curso sólo se pueden encontrar picnidios estromáticos, pero alejado del extremo apical, en la porción de las ramas y follaje que contiene tejido vegetal de más de un año, sólo es posible detectar la presencia ascocarpos estromáticos ya maduros, o sobremaduros. Vale decir, en este tipo de muestra no selectiva, se podrían encontrar picnidios y ascocarpos estromáticos aparentemente con distintos comportamientos de colonización de tejidos del hospedante, lo que sólo podría ser debidamente interpretado, si se conoce adecuadamente el ciclo de vida de C. tropica en P. saligna.

La constatación realizada en el presente trabajo, respecto de que los ascos de C. tropica en $P$. saligna, maduran secuencialmente (figuras $1 \mathrm{~L} \mathrm{y}$ 2D), aspecto importante a considerar en las descripciones de tipo morfológicas y fisiológicas, es concordante con lo señalado por Minter (2006a) para esta especie, y por Speer (1981) para C. brasiliensis sobre $P$. lambertii.

Como proceso biológico, en el ciclo de vida de $C$. tropica en $P$. saligna propuesto en el presente estudio (figura 2), se representa lo que constituiría la norma de los eventos allí involucrados. No se descarta que puedan existir casos excepcionales de carácter puntual, que obedezcan también a situaciones muy específicas, como por ejemplo condiciones microecológicas dentro de un mismo árbol, y que excedan el marco de esta representación. Del mismo modo, el ciclo biológico de $C$. tropica aquí propuesto, para el área de estudio ya señalado, puede presentar un desfase cronológico, dependiendo de la latitud y altitud del sitio ecológico en el que se desarrolle $P$. saligna.

En base a la presencia de fructificaciones del anamorfo y del teleomorfo ya descritas, en el presente estudio se pudo constatar que C. tropica manifestó una relación unívoca entre el ataque de hojas y el ataque de ramas de $P$. saligna, vale decir, siempre que hubo ataque de follaje, también 
lo hubo en la porción de la rama que lo contenía (figura $1 \mathrm{ABCJ}$ ). Esto difiere con Butin y Peredo (1986), quienes señalan que este agente se presenta inicialmente en hojas vivas y ocasionalmente sobre la corteza de ramas jóvenes. También difiere con Speer (1981) quien reporta que C. brasiliensis en $P$. lambertii coloniza exclusivamente hojas, y la colonización simultánea de hojas y tallos es muy rara. Y por último, también difiere con las descripciones de las siete especies de Corynelia reconocida hasta ahora, en las que se señala, según la especie en cuestión, que las colonias de este hongo se encuentran principalmente en las hojas y son menos frecuentes, o no han sido observadas en tallos o ramas del año en curso (Minter 2006 abcdefg). En los ejemplares de $P$. saligna afectados por el ataque de $C$. tropica, el desarrollo de los síntomas y de las estructuras fructíferas aquí referidas, además de estar siempre presentes tanto en las hojas, como en los tejidos de las ramas nuevas aún verdes, correspondientes al último período vegetativo, también fue detectada en los frutos (figura 3AB). Los trabajos de carácter morfológicos y taxonómicos relacionados con la presencia de $C$. tropica en $P$. saligna son muy escasos, y en general también, el reporte de especies de Corynelia en los frutos de sus hospedantes, es prácticamente inexistente. Una excepción a ello lo constituye lo reportado por Hood (1985) quien, para Nueva Zelanda, señala la presencia de $C$. tropica en hojas, ramas y frutos de Podocarpus totara, P. hallii, P. nivalis, y P. acutifolius. En el caso $C$. tropica en $P$. saligna, el que en trabajos anteriores no se haya reportado la presencia de este patógeno en los frutos, podría deberse a que, siendo este hospedante una especie dioica, por razones de probabilidad de muestreo, podría ser que el material de estudio utilizado haya sido obtenido sólo de árboles masculinos.

Como éstas, hay varias otras imprecisiones y contradicciones que se pueden detectar en la bibliografía respecto de la identificación y descripción tanto de C. tropica, como de otras especies del género Corynelia. Ello puede tener su origen en que las fechas de colecta de muestras se hayan concentrado mayoritariamente en el periodo estival, en que el número de éstas haya sido muy reducido, o en que la calidad del material de estudio no haya sido la más adecuada. Todos estos factores pueden llegar a tener incidencia tanto en la taxonomía, como en la nomenclatura, y probablemente también en la correcta descripción de algunas de las especies de este género, actualmente reconocidas.

En la bibliografía específica hay poca información respecto de los efectos que C. tropi$c a$ puede tener en sus hospedantes. Al menos en Nueva Zelanda, Hood (1985) señala que C. tropica causa un daño insignificante en las especies de Podocarpus en las que allí este patógeno ha sido reportado. En el presente estudio se pudo detectar que, dependiendo del sitio en el que se encuentren presentes los ejemplares de $P$. saligna, el ataque de $C$. tropica puede llegar a causar fuertes defoliaciones (figura 4B). De hecho, los ataques más intensos registrados durante los muestreos, se detectaron en árboles expuestos a ambientes con poca ventilación y/o poca luminosidad. Este es un aspecto interesante de investigar más en profundidad, teniendo en cuenta tanto el uso ornamental que se le da al P.saligna, como el potencial uso comercial que él podría llegar a tener si resultase atrayente para los programas de diversificación de las plantaciones con especies nativas. Según Speer (1981), en Brasil, donde P. lambertii es una especie de interés económico, la presencia $C$. brasiliensis se traduce en una disminución del crecimiento y en casos particulares la muerte de individuos jóvenes. Cabe señalar que todos los síntomas y signos de $C$. tropica aquí descritos se pudieron detectar tanto en árboles de $P$. saligna regenerados naturalmente, como en ejemplares plantados artificialmente. Este también es un aspecto que se debería considerar al momento de optar por alguno de los usos potenciales que se le quiera dar a esta especie.

Desde el punto de vista de la Patología Forestal, los resultados aquí generados pueden llegar 
a constituir una herramienta de apoyo para quienes deseen incursionar en estudios de medidas tanto profilácticas como de control, ya que aportan información fenológica detallada sobre la relación huésped-hospedante. En forma anexa, la información aquí generada respecto de los procesos de inicio y de desarrollo de las diferentes estructuras fructíferas involucradas en el ciclo de vida de C.tropica en $P$. saligna, puede también contribuir para la profundización de estudios de carácter morfológicos y fisiológicos, como también para eventuales revisiones de tipo taxonómicas relacionadas con este patógeno.

Entre los aspectos más relevantes observados en el presente estudio, se puede señalar que:

- El ciclo de vida de $C$. tropica en $P$. saligna es anual y muy regular.

- La fase asexual de C. tropica, representada por la formación de picnidios estromáticos está siempre presente en el ciclo de vida de este patógeno, y luego de aproximadamente seis meses, sobre ellos se origina la formación de los ascocarpos que re- presentan la fase sexual de este parásito.

- Siempre que el follaje de P. saligna fue atacado por $C$. tropica, las ramas aún verdes correspondientes al último periodo vegetativo, también fueron afectadas.

- Corynelia tropica ataca también a los frutos de P. saligna.

- Los ataques más intensos causado por C. tropica en ejemplares de $P$. saligna se registraron en ambientes con poca ventilación y/o poca luminosidad.

\section{AGRADECIMIENTOS}

A la Dirección de Investigación y Desarrollo de la Universidad Austral de Chile por el financiamiento del Proyecto S-92-12, que hizo posible este estudio. A Walter Augusto García Retamal, alumno de Ingeniería Forestal, Becario de Estímulo Universitario, por su colaboración en la colecta del material de estudio. A Cristóbal F. Osorio F. por su aporte en la diagramación de las figuras que acompañan este trabajo.

\section{REFERENCIAS}

Butin, H; Peredo, HL. (1986). Hongos parásitos en coníferas de América del Sur con especial referencia a Chile. Bibliotheca Mycologica, Cramer, Berlin. 100 p. (Band 101).

Benny, GL; Samuelson, DA; Kimbrough, JW. (1985). Studies on the Coryneliales. II. Taxa parasitic on podocarpaceae: Corynelia. Botanical Gazette. 146(2): 238-251.

Diaz-vaz, JE. (1987). Anatomía de madera de Podocarpus saligna D. Don. Bosque 7(2): 129-131.

Donoso, C. (1978). Dendrología. Árboles y Arbustos Chilenos. Universidad de Chile, Facultad de Ciencias Forestales, Departamento de Silvicultura. 142 p. (Manual No 2).

Fitzpatrick, HM. (1920a). Monograph of the Coryneliaceae. Mycologia 12: 206-237.
Fitzpatrick, HM. (1920b). Monograph of the Corineliaceae. Mycologia 12(5): 239-267. (Continuated from the July number).

Fitzpatrick, HM. (1942). Revisionary studies in the Coryneliaceae. Mycologia 34(5): 464-488.

Hood, IA. (1985). Algal and fungal leaf spots of native plants. Foresta Pathology in New Zealand. 8 p. $\left(\mathrm{N}^{\mathrm{o}} 12\right)$.

Minter, DW. (2006a). Corynelia brasiliensis. IMI Descriptions of Fungi and Bacteria. s.p. ( $\left.\mathrm{N}^{\mathrm{o}} 1661\right)$.

Minter, DW. (2006b). Corynelia jamaicensis. IMI Descriptions of Fungi and Bacteria. s.p. ( $\left.\mathrm{N}^{\mathrm{o}} 1662\right)$.

Minter, DW. (2006c). Corynelia nipponensis. IMI Descriptions of Fungi and Bacteria. s.p. ( $\left.\mathrm{N}^{\mathrm{o}} 1663\right)$. 
Minter, DW. (2006d). Corynelia oreophila. IMI Descriptions of fungi and Bacteria. s.p. ( $\left.\mathrm{N}^{\mathrm{o}} 1664\right)$.

Minter, DW. (2006e). Corynelia portoricensis. IMI Descriptions of Fungi and Bacteria. s.p. $\left(\mathrm{N}^{\mathrm{o}}\right.$ 1665).

Minter, DW. (2006f). Corynelia tropica. IMI Descriptions of Fungi and Bacteria. s.p. ( $\left.\mathrm{N}^{\mathrm{o}} 1666\right)$.

Minter, DW. (2006g). Corynelia uberata. IMI Descriptions of Fungi and Bacteria. s.p. ( $\left.\mathrm{N}^{\mathrm{o}} 1667\right)$.

Morales, J. (2013). Información tecnológica de productos forestales no madereros del bosque nativo en Chile. Antecedentes silvícolas y tecnológicos
Podocarpus saligna (Mañío de hojas largas).Corporación Nacional Forestal- Instituto Forestal, Chile. s.p.

Osorio, M. (1996). Ciclo vital de Corynelia tropica en Podocarpus saligna. Resúmenes, V Congreso Nacional de Fitopatología, Temuco, Chile, 14-16 Noviembre, 1995. Fitopatología 31(3):165-183.

Speer, EO. (1981). Recherches sur la biologie des champignons corticoles des ligneux. These Doctor es Sciences Naturelles, Universite Louis Pasteur de Strasbourg. 133 p. Tome 1 (Texte).

Spegazzini, CL. (1923). Quinta contribución a la micología chilena. Revista chilena de historia natural. 27: 54-62. 